\title{
Controlled Strategies Using DC Voltage for Asymmetric Twin Converter for a High Power STATCOM
}

\author{
D.Sadakar ${ }^{1}$, Mrs.G.Indirarani ${ }^{2}$ \\ ${ }^{1}$ (Dept of EEE, VBIT College, JNTUH, Hyderabad, India,email:sada231@gmail.com) \\ ${ }^{2}$ (Asst.Professor, Dept of EEE, VBIT College,JNTUH, Hyderabad, India,email:indirarani.guntu@gmail.com)
}

\begin{abstract}
The proposed controller can balance individual dc capacitor voltages when H-bridges run with different switching patterns and have parameter variations. It has two advantages: 1) the controller can work well in all operation modes (the capacitive mode, the inductive mode, and the standby mode) and 2) the impact of the individual $d c$ voltage controller on the voltage quality is small. This topology suggests further improvement Here we have to using fuzzy logic controllers in the control scheme to reduce total harmonic distortion. A three phase cascaded H-bridge inverter this control method uses a discrete-time model of the system to predict the future value of the current for all voltage vectors, and selects the vector which minimizes a cost function. Analytical solutions of pulse width-modulation (PWM) strategies for multilevel inverters are used to identify that alternative phase opposition disposition PWM for diode clamped inverters produces the same harmonic performance as phase-shifted carrier PWM for cascaded inverters, and hybrid PWM for hybrid inverters, when the carrier frequencies are set to achieve the same number of inverter switch transitions over each fundamental cycle. In order to improve the performance, a phase-shifted carrier based pulse width modulation technique is used. A mathematical model of the system is derived, based on which a controller for the scheme is designed. The effectiveness of the scheme is verified through detailed simulation study.
\end{abstract}

Index Terms: DC voltage regulation, fuzzy logic controllers, voltage source converter (VSC), Pulse width modulation (PWM), static compensator (STATCOM)

\section{Introduction}

The static synchronous compensator (STATCOM) is a flexible ac transmission system device, which is connected as a shunt to the power system, for generating or absorbing reactive power [5]. A STATCOM works in the capacitive mode if it injects reactive power to the power system and in the inductive mode it absorbs reactive power from the power system. A multi pulse converter uses more than one voltage source converter (VSC), with common dc link, operating with nearly fundamental switching frequency, and the output of each module is connected in series through the multi pulse transformer. By adjusting the triggering pulses of different VSCs, specified total harmonic distortion (THD) of the injected current is achieved with reduced switching losses as compared to that of single-VSC-based solution. The major drawback of this scheme is the high cost and complex structure of the bulky multi pulse transformer. Multilevel converter technology is a very efficient alternative for medium voltage and high-power applications and also for other applications where high-quality voltages and currents are required [1], [2]. The other commonly used multilevel topology, i.e., cascaded converter topology comprises several single-phase H-bridge/full-bridge converters, with separate dc links. The following are the two associated problems of this topology:

1) The size of the dc-link capacitor required is high because the instantaneous power involved with each module varies at twice the fundamental frequency.

2) Regulating voltage across a large number of self supported dc-link capacitors makes the controller design complex.

To address some of the aforementioned limitations in multilevel converters, a four-level open ended transformer-based multilevel converter, shown in Fig. 1, is proposed in [3]. When the multilevel converter is applied to STATCOM, each of the cascaded H-bridge converters should be equipped [9] with a galvanically isolated and floating dc capacitor without any power source or circuit. This topology uses a reduced number of components (12 controlled switches with [3] anti parallel diodes) as compared to the diode clamped topology (18 controlled switches with anti parallel diodes plus 18 diodes) [5]. Moreover, in this case, semiconductor switches are arranged as VSC, which enables easier structural layout and reduced driver circuit complexity.

Therefore, standard VSC power modules [include six insulated-gate bipolar transistors (IGBTs) and their driver circuits in one package] can be used instead of discrete components. Moreover, this topology utilizes cascade connection of three-phase VSCs, and hence, the size of the dc-link capacitor is less as compared to that 
in cascaded H-bridge multilevel converter. Most power electronics technologies, including control skills, are required to convert the dc into ac power.

To address this limitation, an asymmetric twin converter topology is proposed in this paper where in only two dc links are used without split-capacitor arrangement, as shown in Fig. 1. Furthermore, the THD of currents supplied to the grid is reduced by selecting a suitable ratio of dc-link voltages of the two VSCs.

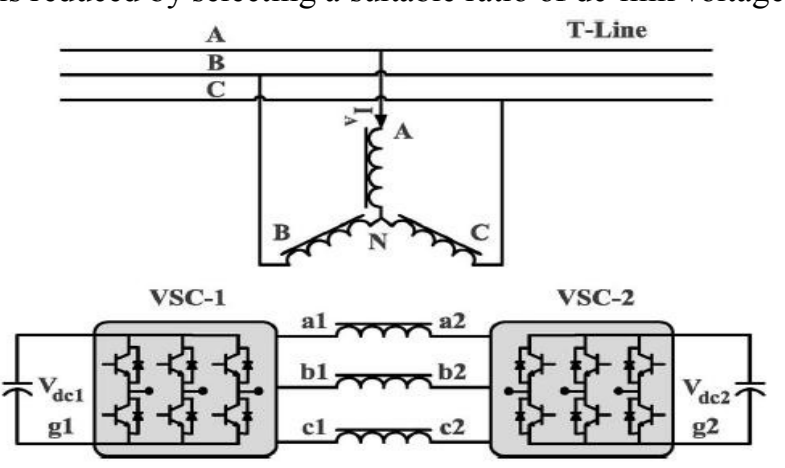

Fig. 1. Asymmetric-twin-converter-topology-based STATCOM

\section{A. Principle of Operation}

\section{Proposed Twin Converter Circuit Topology}

The proposed asymmetric-twin-converter-based multilevel topology, comprising two VSCs, is shown in Fig. 1. Low voltage (LV) windings of the transformer are connected differentially between two 2-level VSCs such that the voltage appearing on the LV side is the difference of the output voltages of two VSCs. Highvoltage (HV) windings, arranged in a star configuration, are connected to the three-phase grid. Leakage inductances of the transformers act as input filter inductances of the STATCOM. Both VSCs operate with separate dc links to produce two-level individual output. Voltages appearing on the LV windings of the transformer are written in terms of output voltages of VSCs as

$$
\begin{aligned}
& e_{a}=e_{a 1 g 1}-e_{a 2 g 2}+e_{g 1 g 2} \\
& e_{b}=e_{b 1 g 1}-e_{b 2 g 2}+e_{g 1 g 2} \\
& e_{c}=e_{c 1 g 1}-e_{c 2 g 2}+e_{g 1 g 2}
\end{aligned}
$$

where $\mathrm{e}_{\mathrm{a}}, \mathrm{e}_{\mathrm{alg} 1}, \mathrm{e}_{\mathrm{a} 2 \mathrm{~g} 2}$, and $\mathrm{e}_{\mathrm{g} 1 \mathrm{~g} 2}$ are the voltages across the LV winding of phase-a, the pole voltage of VSC-1, the pole voltage of VSC-2, and the voltage difference between negative dc-link terminals of the two VSCs, respectively. Since both VSCs have separate dc links, the sum of the LV winding phase currents should be zero

$$
\mathrm{i}_{\mathrm{a}}+\mathrm{i}_{\mathrm{b}}+\mathrm{i}_{\mathrm{c}}=0
$$

Furthermore, the sum of instantaneous values of grid voltages is equal to zero

$$
\mathrm{v}_{\mathrm{A}}+\mathrm{v}_{\mathrm{B}}+\mathrm{v}_{\mathrm{C}}=0
$$

The sum of the LV winding voltages is given by

$$
e_{a}+e_{b}+e_{c}=\frac{N_{L V}}{N_{H V}}\left(v_{A}+v_{B}+v_{C}\right)-r\left(i_{a}+i_{b}+i_{c}\right)-\frac{L d\left(i_{a}+i_{b}+i_{c}\right)}{d t}
$$

where $\mathrm{r}$ and $\mathrm{L}$ are the resistance and leakage inductance as measured from the LV side, respectively, and $\mathrm{N}_{\mathrm{LV}} / \mathrm{N}_{\mathrm{HV}}$ is the turns ratio. Substituting (2) and (3) into (4) gives

$$
\mathrm{e}_{\mathrm{a}}+\mathrm{e}_{\mathrm{b}}+\mathrm{e}_{\mathrm{c}}=0
$$

Substituting LV voltages from (1) in (5) results in

Substituting the value of eg1g2 in (1) yields

$$
\begin{aligned}
\mathrm{e}_{\mathrm{g} 1 \mathrm{~g} 2}= & -\frac{1}{3}\left(\mathrm{e}_{\mathrm{a} 1 \mathrm{~g} 1}-\mathrm{e}_{\mathrm{a} 2 \mathrm{~g} 2}\right) \\
& -\frac{1}{3}\left(\mathrm{e}_{\mathrm{b} 1 \mathrm{~g} 1}-\mathrm{e}_{\mathrm{b} 2 \mathrm{~g} 2}\right) \\
& -\frac{1}{3}\left(\mathrm{e}_{\mathrm{c} 1 \mathrm{~g} 1}-\mathrm{e}_{\mathrm{c} 2 \mathrm{~g} 2}\right)
\end{aligned}
$$




$$
\left(\begin{array}{l}
e_{a} \\
e_{b} \\
e_{c}
\end{array}\right)=\frac{1}{3}\left(\begin{array}{ccc}
2 & -1 & -1 \\
-1 & 2 & -1 \\
-1 & -1 & 2
\end{array}\right)\left(\begin{array}{l}
e_{a 1 g 1}-e_{a 2 g 2} \\
e_{b 1 g 1}-e_{b 2 g 2} \\
e_{c 1 g 1}-e_{c 2 g 2}
\end{array}\right)
$$

The relation between LV winding voltages and pole voltages is expressed in (7). Pole voltages depend on the conduction state of the switches in VSC-1 and VSC-2. A total of $26=64$ different combinations of states of the switches is possible, the ratio of dc-link voltages of VSCs $\mathrm{V}_{\mathrm{dc} 1}: \mathrm{V}_{\mathrm{dc} 2}$ should be equal to 1:0.366 for better performance. Using this, the voltage space vector plot corresponding to unique switching states is shown in Fig. 3.3. Out of 64 switching states, 49 states produce unique phase voltages, and 25 voltage steps are viable in the $\mathrm{LV}$-side voltage. The line voltages of the LV side $\mathrm{e}_{\mathrm{ab}}, \mathrm{e}_{\mathrm{bc}}$, and $\mathrm{e}_{\mathrm{ca}}$ are expressed as pole voltages using (1)

$$
\begin{aligned}
& \mathrm{e}_{\mathrm{ab}}=\mathrm{e}_{\mathrm{a}}-\mathrm{e}_{\mathrm{b}}=\mathrm{e}_{\mathrm{a} 1 \mathrm{~g} 1}-\mathrm{e}_{\mathrm{a} 2 \mathrm{~g} 2}-\mathrm{e}_{\mathrm{b} 1 \mathrm{~g} 1}+\mathrm{e}_{\mathrm{b} 2 \mathrm{~g} 2} \\
& \mathrm{e}_{\mathrm{bc}}=\mathrm{e}_{\mathrm{b}}-\mathrm{e}_{\mathrm{c}}=\mathrm{e}_{\mathrm{b} 1 \mathrm{~g} 1}-\mathrm{e}_{\mathrm{b} 2 \mathrm{~g} 2}-\mathrm{e}_{\mathrm{c} 1 \mathrm{~g} 1}+\mathrm{e}_{\mathrm{c} 2 \mathrm{~g} 2} \\
& \mathrm{e}_{\mathrm{ca}}=\mathrm{e}_{\mathrm{c}}-\mathrm{e}_{\mathrm{a}}=\mathrm{e}_{\mathrm{c} 1 \mathrm{~g} 1}-\mathrm{e}_{\mathrm{c} 2 \mathrm{~g} 2}-\mathrm{e}_{\mathrm{a} 1 \mathrm{~g} 1}+\mathrm{e}_{\mathrm{a} 2 \mathrm{~g} 2}
\end{aligned}
$$

For $\mathrm{v}_{\mathrm{dc} 2}=0.5 \mathrm{v}_{\mathrm{dc} 1}$, depending on the state of switches, voltage waveforms of $\mathrm{e}_{\mathrm{ab}}, \mathrm{e}_{\mathrm{bc}}$, and $\mathrm{e}_{\mathrm{ca}}$ has seven different steps. This is same as the number of steps obtained in the line voltage of four-level diode clamped multilevel converter. For $\mathrm{v}_{\mathrm{dc} 2}=0.366 \mathrm{v}_{\mathrm{dc}}$, nine different steps are observed in the line voltage waveforms, which is the same as that in four-level diode clamped converter with the capacitor voltage ratio $\mathrm{v}_{\mathrm{dc} 1}: \mathrm{v}_{\mathrm{dc} 2}: \mathrm{v}_{\mathrm{dc} 3}$ equal to 0.33:0.66:0.33. This makes the proposed scheme equivalent to a four-level converter.

\section{B. PWM Strategy}

LV voltage ea takes one of the 25 values given by (7), depending on the state of the switches. The switching state is decided by the modulating waveform and the PWM strategy used. Selective harmonic elimination method (SHEM), space vector modulation (SVM), or carrier-based PWM (CB-PWM)

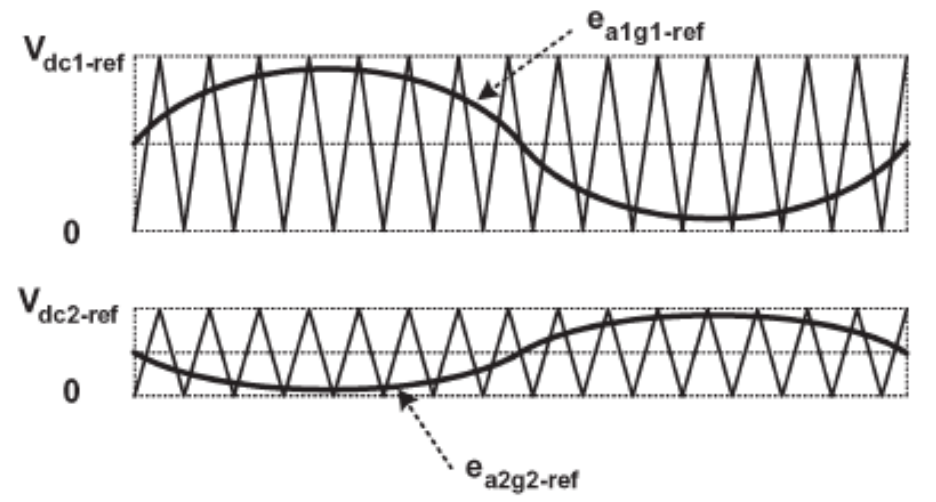

Fig. 2. Comparison of modulating and carrier waveforms for PS CB-PWM.

techniques are commonly used for high-power applications. SHEM is limited in use because of its slow dynamic response. Realization of SVM for multilevel converter requires an algorithm for the identification of sector. The presence of large number of sectors makes the implementation complex. Hence, the use of phaseshifted (PS) CB-PWM is suggested for the proposed topology. This PWM technique expects the controller to generate individual modulating waveforms for each inverter output $\mathrm{e}_{\mathrm{a} 1 \mathrm{~g} 1}, \mathrm{e}_{\mathrm{b} 1 \mathrm{~g} 1}, \mathrm{e}_{\mathrm{c} 1 \mathrm{~g} 1}, \mathrm{e}_{\mathrm{a} 2 \mathrm{~g} 2}, \mathrm{e}_{\mathrm{b} 2 \mathrm{~g} 2}$, and $\mathrm{e}_{\mathrm{c} 2 \mathrm{~g} 2}$. Each modulating waveform is compared with a carrier waveform to determine the switching state of the corresponding inverter devices. This is similar to the PS CB-PWM technique used in H-bridge cascaded converters. For two H-bridges per phase, the resultant waveform of ac voltages is the sum of individual converter voltages. Therefore, carrier waveforms are 180。 PS from each other to cancel the carrier frequency harmonics. However, in the case of asymmetric twin converter topology, the shift in carriers is not required because the resultant waveform is the difference of two ac voltages. Comparison of modulating and carrier signals for phase-a is shown in Fig. 2. Modulated converter voltages $\mathrm{e}_{\mathrm{a} 1 \mathrm{~g} 1}, \mathrm{e}_{\mathrm{a} 2 \mathrm{~g} 2}$, and ea for the simulated case of $\mathrm{V}_{\mathrm{dc} 1}=805 \mathrm{~V}, \mathrm{~V}_{\mathrm{dc} 2}=294 \mathrm{~V}$, fundamental frequency $\mathrm{f}=50 \mathrm{~Hz}$, carrier frequency $\mathrm{f}_{\mathrm{c}}=900 \mathrm{~Hz}$, and modulation index $\mathrm{m}=0.9$. The harmonic spectra of the voltage ea. The absence of low-order harmonics confirms the operation of PWM technique. Dominant harmonics are present at the sideband of twice the carrier frequency. Although the sidebands of carrier frequency are also present, their magnitude is less than that of twice the carrier frequency. 


\section{Development Of The Equivalent Circuit Of The System}

For the purpose of analysis, an equivalent circuit of the proposed STATCOM is derived. Transformer is represented by equivalent series combination of inductances, resistances, and voltage sources. To model the losses in two VSCs, two resistances $r_{1}$ and $r_{2}$ are placed in parallel to the two dc links. The governing equations of the proposed system can be derived as

$$
s\left(\begin{array}{c}
i_{a} \\
i_{b} \\
i_{c}
\end{array}\right)=\left(\begin{array}{ccc}
-\frac{r w_{b}}{L} & 0 & 0 \\
0 & -\frac{r w_{b}}{L} & 0 \\
0 & 0 & -\frac{r w_{b}}{L}
\end{array}\right)\left(\begin{array}{l}
i_{a} \\
i_{b} \\
i_{c}
\end{array}\right)+\frac{w_{b}}{L}\left(\begin{array}{l}
-e_{a}+V_{a} \\
-e_{b}+V_{b} \\
-e_{c}+V_{c}
\end{array}\right)
$$

where $L$ is defined as $\omega_{b} 1 / z_{b a s e} .1, \omega_{b}$, and $z_{b a s e}$ are the leakage inductance, base frequency, and base impedance of STATCOM. All the parameters and variables are expressed in per-unit (p.u.) system. Equation (9) is transformed into dq0 reference frame, which has been defined in the Appendix. The system variables in the dq0 frame are expressed as follows:

$$
s\left(\begin{array}{c}
i_{d} \\
i_{q}
\end{array}\right)=\left(\begin{array}{cc}
-\frac{r w_{b}}{L} & w \\
-w & -\frac{r w_{b}}{L}
\end{array}\right)\left(\begin{array}{l}
i_{d} \\
i_{q}
\end{array}\right)+\frac{w_{b}}{L}\left(\begin{array}{c}
-e_{d 1}+e_{d 2}+|V| \\
-e_{q 1}+e_{q 2}
\end{array}\right)
$$

where $\mathrm{i}_{\mathrm{d}}$ and $\mathrm{i}_{\mathrm{q}}$ are the $\mathrm{d}$ - and $\mathrm{q}$-axis components of LV-side currents. $\mathrm{e}_{\mathrm{d} 1}$ and $\mathrm{e}_{\mathrm{q} 1}$ are the voltage components of VSC-1, and $\mathrm{e}_{\mathrm{d} 2}$ and $\mathrm{e}_{\mathrm{q} 2}$ are the voltage components of VSC-2. Equation (10) interrelates the ac parameters of the STATCOM with those of the grid. The dependence between dc and ac parameters of STATCOM is derived using instantaneous power balance equations. The following equation gives the power balance condition between the ac and dc links of VSC-1:

$$
\mathrm{v}_{\mathrm{dc} 1} \mathrm{i}_{\mathrm{dc} 1}=\frac{3}{2}\left(\mathrm{e}_{\mathrm{d} 1} \mathrm{i}_{\mathrm{d}}+\mathrm{e}_{\mathrm{q} 1} \mathrm{i}_{\mathrm{q}}\right)
$$

The current flowing through the dc-link capacitor $\mathrm{c}_{1}$ is related to the dc-link voltage vdc1 as follows:

$$
\mathrm{sv}_{\mathrm{dc} 1}=\mathrm{w}_{\mathrm{b}} \mathrm{C}_{1}\left(\mathrm{i}_{\mathrm{dc} 1}-\frac{\mathrm{v}_{\mathrm{dc} 1}}{\mathrm{r}_{1}}\right)
$$

where $\mathrm{C}_{1}$ is defined as $1 /\left(\omega_{\mathrm{b}} \mathrm{c}_{1} \mathrm{z}_{\mathrm{base}}\right)$. Substituting $\mathrm{i}_{\mathrm{dcl}}$ from (11)

$$
\mathrm{sv}_{\mathrm{dc} 1}=\mathrm{w}_{\mathrm{b}} \mathrm{C}_{1}\left(\frac{3}{2 \mathrm{v}_{\mathrm{dc} 1}}\left(\mathrm{e}_{\mathrm{d} 1} \mathrm{i}_{\mathrm{d}}+\mathrm{e}_{\mathrm{q} 1} \mathrm{i}_{\mathrm{q}}\right)-\frac{\mathrm{v}_{\mathrm{dc} 1}}{\mathrm{r}_{1}}\right)
$$

Similarly, the governing equation for VSC-2 is expressed as

$$
\mathrm{sv}_{\mathrm{dc} 2}=\mathrm{w}_{\mathrm{b}} \mathrm{C}_{2}\left(\frac{-3}{2 \mathrm{v}_{\mathrm{dc} 2}}\left(\mathrm{e}_{\mathrm{d} 2} \mathrm{i}_{\mathrm{d}}+\mathrm{e}_{\mathrm{q} 2} \mathrm{i}_{\mathrm{q}}\right)-\frac{\mathrm{v}_{\mathrm{dc} 2}}{\mathrm{r}_{2}}\right)
$$

Equations (10), (13), and (14) represent the behavior of the system. These equations are used in the following section.

\section{Development Of The Controller}

The proposed asymmetric-twin-converter-based STATCOM has two dc-link voltages $\mathrm{v}_{\mathrm{dcl}}$ and $\mathrm{v}_{\mathrm{dc} 2}$. The controller should regulate these two dc-link voltages and govern the total reactive power flowing to/from the STATCOM. The total active power required to overcome losses and regulate dc-link voltages is drawn by STATCOM from the grid. This active power needs to be redistributed among the two dc links. The distribution should ensure that the two dc-link voltages $\mathrm{v}_{\mathrm{dc} 1}$ and $\mathrm{v}_{\mathrm{dc} 2}$ are maintained equal to their corresponding reference values. The suitable controller to achieve these objectives is discussed in this section.

\section{Current Control}

The overall system is represented by two coupled differential equations. To decouple them, two variables $\mathrm{x}_{1}$ and $\mathrm{x}_{2}$ are defined such that

$$
-e_{d 1}+e_{d 2}=\frac{L}{w_{b}}\left(x_{1}-w i_{q}\right)-|V|
$$




$$
-\mathrm{e}_{\mathrm{q} 1}+\mathrm{e}_{\mathrm{q} 2}=\frac{\mathrm{L}}{\mathrm{w}_{\mathrm{b}}}\left(\mathrm{x}_{2}-\mathrm{wi}_{\mathrm{d}}\right)
$$

By combining (10) with (15) and (16), the decoupled system equations are obtained as follows:

$$
s\left(\begin{array}{c}
i_{d} \\
i_{q}
\end{array}\right)=\left(\begin{array}{cc}
-\frac{r w_{b}}{L} & 0 \\
0 & -\frac{r w_{b}}{L}
\end{array}\right)\left(\begin{array}{l}
i_{d} \\
i_{q}
\end{array}\right)+\frac{w_{b}}{L}\left(\begin{array}{l}
x_{1} \\
x_{2}
\end{array}\right)
$$

Applying small-signal analysis on the decoupled system of (17), the small-signal plant transfer function is derived as

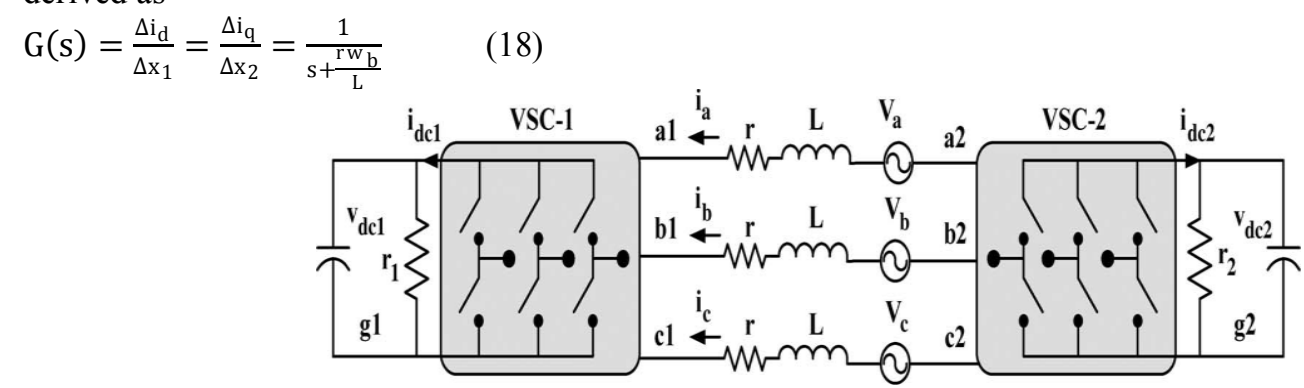

Fig. 3 .Equivalent circuit diagram of the proposed STATCOM.

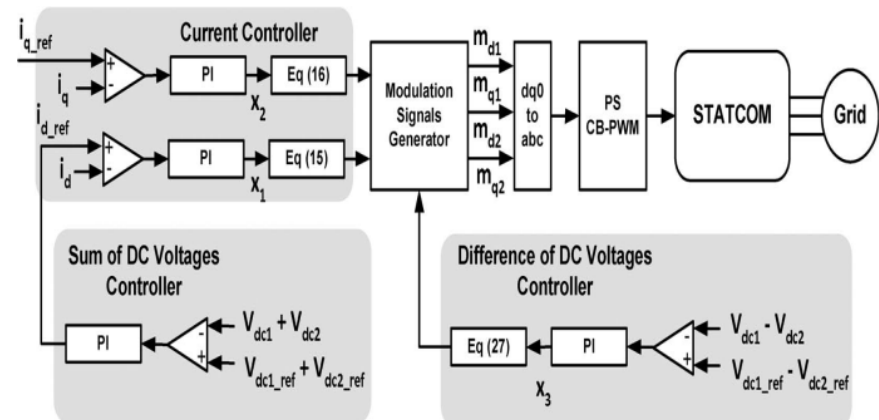

Fig. 4. Controller for STATCOM.

Control variables $x_{1}$ and $x_{2}$ govern the system currents $i_{d}$ and $i_{q}$, respectively, as per the differential equation (17). Therefore, current control is achieved by controlling variables $x_{1}$ and $x_{2}$ using the errors between reference values and actual currents, as given by

$$
\begin{aligned}
& \mathrm{x}_{1}=\mathrm{k}_{\mathrm{p} 1}\left(\mathrm{i}_{\mathrm{d}_{\text {_ref }}}-\mathrm{i}_{\mathrm{d}}\right)+\mathrm{k}_{\mathrm{i} 1} \int\left(\mathrm{i}_{\mathrm{d}_{\text {_ref }}}-\mathrm{i}_{\mathrm{d}}\right) \mathrm{dt} \\
& \mathrm{x}_{2}=\mathrm{k}_{\mathrm{p} 2}\left(\mathrm{i}_{\mathrm{q}_{\text {-ref }}}-\mathrm{i}_{\mathrm{q}}\right)+\mathrm{k}_{\mathrm{i} 2} \int\left(\mathrm{i}_{\mathrm{q}_{\mathrm{I}_{\text {ref }}}}-\mathrm{i}_{\mathrm{q}}\right) \mathrm{dt}
\end{aligned}
$$

Required LV voltages $e_{\mathrm{d} 1}-\mathrm{e}_{\mathrm{d} 2}$ and $\mathrm{e}_{\mathrm{q} 1}-\mathrm{e}_{\mathrm{q} 2}$ are derived by using these values of $\mathrm{x}_{1}$ and $\mathrm{x}_{2}$ in (15) and (16). To generate these voltages, modulation signals for the VSCs are derived as follows:

$$
\mathrm{m}_{\mathrm{d} 1}=\frac{\mathrm{e}_{\mathrm{d} 1}}{\mathrm{v}_{\mathrm{dc} 1}} ; \mathrm{m}_{\mathrm{q} 1}=\frac{\mathrm{e}_{\mathrm{q} 1}}{\mathrm{v}_{\mathrm{dc} 1}} ; \mathrm{m}_{\mathrm{d} 2}=\frac{\mathrm{e}_{\mathrm{d} 2}}{\mathrm{v}_{\mathrm{dc} 2}} ; \mathrm{m}_{\mathrm{q} 2}=\frac{\mathrm{e}_{\mathrm{q} 2}}{\mathrm{v}_{\mathrm{dc} 2}}
$$

An inner current controller is implemented using (15), (16) and (19)-(21). As shown in Fig.4.

The inner current controller generates the modulating waveforms of $L V$ voltages $\left(\mathrm{m}_{\mathrm{d} 1} \mathrm{~V}_{\mathrm{dc} 1}-\mathrm{m}_{\mathrm{d} 2} \mathrm{v}_{\mathrm{dc} 2}\right)$ and $\left(\mathrm{m}_{\mathrm{q} 1} \mathrm{~V}_{\mathrm{dc} 1}-\mathrm{m}_{\mathrm{q} 2} \mathrm{~V}_{\mathrm{dc} 2}\right)$. However, modulating waveforms for individual VSCs $\mathrm{m}_{\mathrm{d} 1}, \mathrm{~m}_{\mathrm{d} 2}, \mathrm{~m}_{\mathrm{q} 1}$, and $\mathrm{m}_{\mathrm{q} 2}$ have to be derived from these LV voltages. This distribution is used to regulate real power exchange between the two VSCs, as given in Section IV-C. Furthermore, the current controller requires the reference current signals $i_{d}$ ref and $\mathrm{i}_{\mathrm{q} \text { ref }}$ as inputs. The phase-locked loop is synchronized with the grid voltage such that $\mathrm{q}$ component of the grid voltage is kept equal to zero. Therefore, the total active and reactive powers absorbed or supplied by the STATCOM are proportional to $\mathrm{i}_{\mathrm{d} \text { ref }}$ and $\mathrm{i}_{\mathrm{q} \text { ref }}$, respectively. The outer cascaded controller generates the reference current signals $i_{d \text { ref }}$ and $\bar{i}_{q}$ ref such that the system variables (total reactive power and two dc-link voltages) are maintained at their respective reference values 


\section{Reactive Power Control}

STATCOMs are commonly used either for transmission line voltage support or for reactive power compensation of load. For voltage support of the transmission line, the reactive current reference $i_{q_{-} \text {ref }}$ is controlled by the deviation of the transmission-line voltage from its nominal value. On the other hand, for load compensation operation, the reactive current reference $\mathrm{i}_{\mathrm{q}}$ ref is controlled by the deviation of source power factor from its required value. In both the aforementioned cases, $\mathrm{i}_{\mathrm{q} \_ \text {ref }}$ will be supplied to the current controller by a higher level controller. The issues pertaining to the higher level controller are kept outside the purview of this paper.

\section{DC Voltage Control}

A dc voltage controller should ensure that the two dc-link voltages $\mathrm{v}_{\mathrm{dc} 1}$ and $\mathrm{v}_{\mathrm{dc} 2}$ are regulated at their reference values. This problem is divided into two separate control objectives: first, to maintain the sum of two dc-link voltages $\left(v_{\mathrm{dc} 1}+\mathrm{v}_{\mathrm{dc} 2}\right)$ that is equal to the sum of their reference values $\left(\mathrm{v}_{\mathrm{dc} 1-\mathrm{ref}}+\mathrm{v}_{\mathrm{dc} 2-\mathrm{ref}}\right)$ and, second, to maintain the difference of the two dc link voltages $\left(\mathrm{v}_{\mathrm{dcl}}-\mathrm{v}_{\mathrm{dc} 2}\right)$ that is equal to the difference of their reference values $\left(\mathrm{v}_{\mathrm{dc} 1-\mathrm{ref}}-\mathrm{v}_{\mathrm{dc} 2-\mathrm{ref}}\right)$.

1) Sum of DC Voltages: The sum of the dc voltages $\left(\mathrm{v}_{\mathrm{dc} 1}+\mathrm{v}_{\mathrm{dc2}}\right)$ increases with the net real power flow from grid to STATCOM and vice versa. In other words, the error in the sum of dc-link voltages $\left(v_{\mathrm{dc} 1}+\mathrm{v}_{\mathrm{dc} 2}-\mathrm{v}_{\mathrm{dc} 1-\mathrm{ref}}-\right.$ $\mathrm{v}_{\mathrm{dc2} 2 \text {-ref }}$ ) indicates the amount of real power to be absorbed from the grid. Hence, the d-axis reference current $\mathrm{i}_{\mathrm{d} \_ \text {ref }}$ is controlled by the error existing between reference and actual dc-link voltages of VSCs.

2) Difference of DC Voltages: System equations (13) and (14) are coupled equations describing the behavior of the dc link voltages. Considering $\mathrm{C}_{1}=\mathrm{C}_{2}=\mathrm{C}$ and subtracting (14) from (13) give

Where

$$
\mathrm{s}\left(\mathrm{v}_{\mathrm{dc} 1}-\mathrm{v}_{\mathrm{dc} 2}\right)=\mathrm{x}_{3}-\mathrm{w}_{\mathrm{b}} \mathrm{C}\left(\frac{\mathrm{v}_{\mathrm{dc} 1}}{\mathrm{r}_{1}}-\frac{\mathrm{v}_{\mathrm{dc} 2}}{\mathrm{r}_{2}}\right)
$$

$$
\mathrm{x}_{3}=\frac{3 \mathrm{w}_{\mathrm{b}} \mathrm{C}}{2}\left[\mathrm{i}_{\mathrm{d}}\left(\frac{\mathrm{e}_{\mathrm{d} 1}}{\mathrm{v}_{\mathrm{dc} 1}}+\frac{\mathrm{e}_{\mathrm{d} 2}}{\mathrm{v}_{\mathrm{dc} 2}}\right)+\mathrm{i}_{\mathrm{q}}\left(\frac{\mathrm{e}_{\mathrm{q} 1}}{\mathrm{v}_{\mathrm{dc} 1}}+\frac{\mathrm{e}_{\mathrm{q} 2}}{\mathrm{v}_{\mathrm{dc} 2}}\right)\right]
$$

Substituting modulation signals from (21) into (23) gives

$$
\begin{gathered}
\mathrm{x}_{3}=\frac{3 \mathrm{w}_{\mathrm{b}} \mathrm{C}}{2}\left[\mathrm{i}_{\mathrm{d}}\left(\mathrm{m}_{\mathrm{d} 1}+\mathrm{m}_{\mathrm{d} 2}\right)+\mathrm{i}_{\mathrm{q}}\left(\mathrm{m}_{\mathrm{q} 1}+\mathrm{m}_{\mathrm{q} 2}\right)\right] \\
\mathrm{x}_{3}=\frac{3 \mathrm{w}_{\mathrm{b}} \mathrm{C}}{2}(\overrightarrow{\mathrm{m}} * \overrightarrow{\mathrm{i}})
\end{gathered}
$$

where the modulation vector $\rightarrow \mathrm{m}=\mathrm{m}_{\mathrm{d} 1}+\mathrm{m}_{\mathrm{d} 2}+\mathrm{j}\left(\mathrm{m}_{\mathrm{q} 1}+\mathrm{m}_{\mathrm{q} 2}\right)$ and the current vector $\rightarrow \mathrm{i}=\mathrm{i}_{\mathrm{d}}+\mathrm{ji}_{\mathrm{q}}$. Considering $\mathrm{r}_{1}=\mathrm{r}_{2}=\mathrm{r}$ and applying small-signal analysis on (22) give the transfer function

$$
\mathrm{H}(\mathrm{s})=\frac{\Delta \mathrm{v}_{\mathrm{dc} 1}-\Delta \mathrm{v}_{\mathrm{dc} 2}}{\Delta \mathrm{x}_{3}}=\frac{1}{\mathrm{~s}+\frac{\mathrm{w}_{\mathrm{b}} \mathrm{C}}{\mathrm{r}}}
$$

Equation (22) gives the relation between the control variable $x_{3}$ and the difference of dc-link voltages $\mathrm{v}_{\mathrm{dc} 1}-\mathrm{v}_{\mathrm{dc} 2}$. Therefore, it is inferred that error $\left(\mathrm{v}_{\mathrm{dc1} 1 \text { ref }}-\mathrm{v}_{\mathrm{dc2} 2 \text { ref }}\right)-\left(\mathrm{v}_{\mathrm{dc} 1}-\mathrm{v}_{\mathrm{dc} 2}\right)$ is to be processed through a proportional-integral controller to obtain the control variable $\mathrm{x}_{3}$. Hence, the difference in power requirement between VSC-1 and VSC-2 is reflected in $\mathrm{x}_{3}$. Using it, $(-\rightarrow \mathrm{m} \bullet-\rightarrow \mathrm{i})$ is determined from (25). To achieve the required power flow between VSCs with low dc-link voltages, the modulation vector $\rightarrow \mathrm{m}$ is maintained in phase with $\rightarrow$ i . Hence

$$
|\overrightarrow{\mathrm{m}}|=\frac{2}{3 \mathrm{w}_{\mathrm{b}} \mathrm{C}|\overrightarrow{\mathrm{l}}|} \mathrm{x}_{3} . \quad \angle \overrightarrow{\Delta \mathrm{m}}=\angle \overrightarrow{\mathrm{i}}
$$

The controller which ensures that the difference of dc voltages $\mathrm{v}_{\mathrm{dcl}}-\mathrm{v}_{\mathrm{dc} 2}$ is maintained equal to the reference $\mathrm{v}_{\mathrm{dc} 1 \text { _ref }}-\mathrm{v}_{\mathrm{dc} 2 \text { _ef }}$ is shown in Fig. 4

\section{Generation of Modulation Signals}

The current controller, generates the signals for primary voltages $e_{\mathrm{d} 1}-e_{\mathrm{d} 2}$ and $\mathrm{e}_{\mathrm{q} 1}-\mathrm{e}_{\mathrm{q} 2}$. These are transformed to modulation signals as follows:

$$
\begin{aligned}
& \mathrm{m}_{\mathrm{d} 1} \mathrm{v}_{\mathrm{dc} 1}-\mathrm{m}_{\mathrm{d} 2} \mathrm{v}_{\mathrm{dc} 2}=\mathrm{e}_{\mathrm{d} 1}-\mathrm{e}_{\mathrm{d} 2} \\
& \mathrm{~m}_{\mathrm{q} 1} \mathrm{v}_{\mathrm{dc} 1}-\mathrm{m}_{\mathrm{q} 2} \mathrm{v}_{\mathrm{dc} 2}=\mathrm{e}_{\mathrm{q} 1}-\mathrm{e}_{\mathrm{q} 2}
\end{aligned}
$$




\section{Fuzzy Logic Controller}

L.A.Zadeh presented the first paper on fuzzy set theory in 1965. Since then, a new language was developed to describe the fuzzy properties of reality, which are very difficult and sometime even impossible to be described using conventional methods. Fuzzy set theory has been widely used in the control area with some application to dc-to-dc converter system. A simple fuzzy logic control is built up by a group of rules based on the human knowledge of system behavior. Matlab /Simulink simulation model is built to study the dynamic behavior of converter.

Furthermore, design of fuzzy logic controller can provide desirable both small signal and large signal dynamic performance at same time, which is not possible with linear control technique. Thus, fuzzy logic controller has been potential ability to improve the robustness of converters. The basic scheme of a fuzzy logic controller is shown in Fig 6 and consists of four principal components such as: a fuzzyfication interface, which converts input data into suitable linguistic values; a knowledge base, which consists of a data base with the necessary linguistic definitions and the control rule set; a decision-making logic which, simulating a human decision process, infer the fuzzy control action from the knowledge of the control rules and linguistic variable definitions; a de-fuzzyfication interface which yields non fuzzy control action from an inferred fuzzy control action.

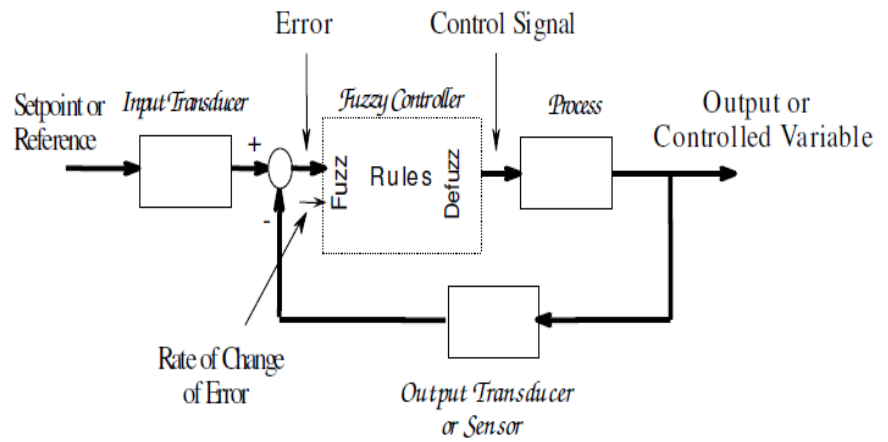

Fig.5. General structure of the fuzzy logic controller

The fuzzy control systems are based on expert knowledge that converts the human linguistic concepts into an automatic control strategy without any complicated mathematical model .

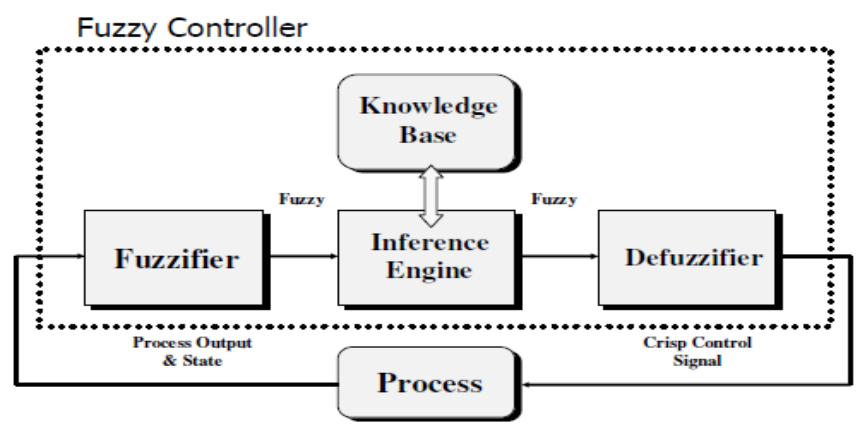

Fig.6. Block diagram of the Fuzzy Logic Controller (FLC) for proposed Converter.

\section{A. Fuzzy Logic Membership Functions:}

Fuzzy controllers do not require an exact mathematical model. Instead, they are designed based on general knowledge of the plant. Fuzzy controllers are designed to adapt to varying operating points. Fuzzy Logic Controllers designed to control the change in voltage of the converter using Mamdani style fuzzy inference system. Two input variables, error (e) and change of error (de) are used in this fuzzy logic system. The single output variable(u) is steady state signal of the converter, nothing but error free response is directly fed to the system. 


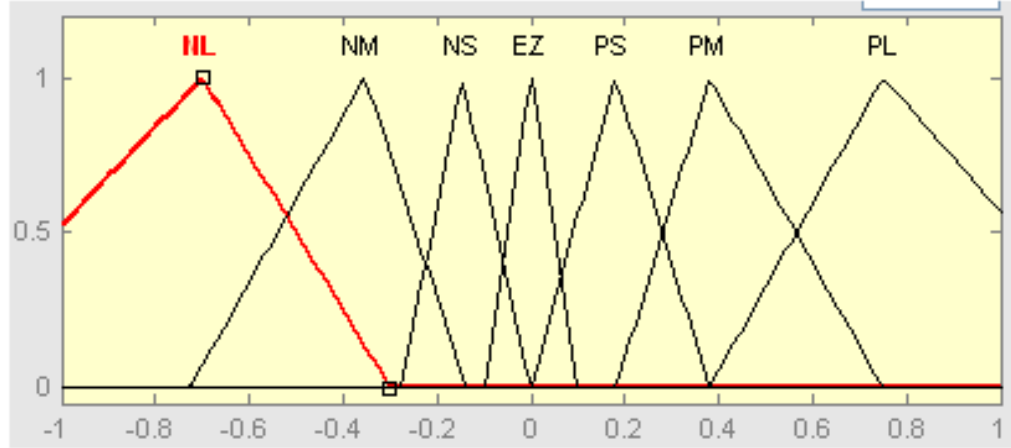

Fig.7. Membership functions for Input, Change in input, Output

Fig.8. Shows the membership functions for input (error(e)), Change in input (change of error (de)), Output variable $(\mathrm{u})$.

\section{B. Fuzzy Logic Rules}

The objective of this dissertation is to control the output voltage of the boost converter. The error and change of error of the output voltage will be the inputs of fuzzylogic controller. These 2 inputs are divided into seven groups; NL: Negative Large, NM: Negative Medium, NS: Negative Small, ZO: Zero Area, PS: Positive small, PM: Positive Medium and PL: Positive Large and its parameter [10]. These fuzzy control rules for error and change of error can be referred that is shown as below.

\begin{tabular}{|c|c|c|c|c|c|c|c|}
\multicolumn{10}{|c|}{ Table1. Fuzzy Rules } \\
\hline Change & \multicolumn{7}{|c|}{ Error } \\
\cline { 2 - 9 } In \\
Error & NB & N & NS & $\mathbf{Z}$ & PS & PM & PB \\
\hline NB & PB & PB & PB & PM & PM & PS & Z \\
\hline NM & PB & PB & PM & PM & PS & Z & Z \\
\hline NS & PB & PM & PS & PS & Z & NM & NB \\
\hline Z & PB & PM & PS & Z & NS & NM & NB \\
\hline PS & PM & PS & Z & NS & NM & NB & NB \\
\hline PM & PS & Z & NS & NM & NM & NB & NB \\
\hline PB & Z & NS & NM & NM & NB & NB & NB \\
\hline
\end{tabular}

Fig.8. Rules for fuzzy logic controller

\section{Matlab Modeling And Simulation Results}

Here Simulation is carried out in two different Conditions,

1). Conventional (PI) Controller Based High Power STATCOM.

2). Intelligence (FUZZY) Controller Based High Power STATCOM.

Case 1: Conventional Controller Based High Power STATCOM

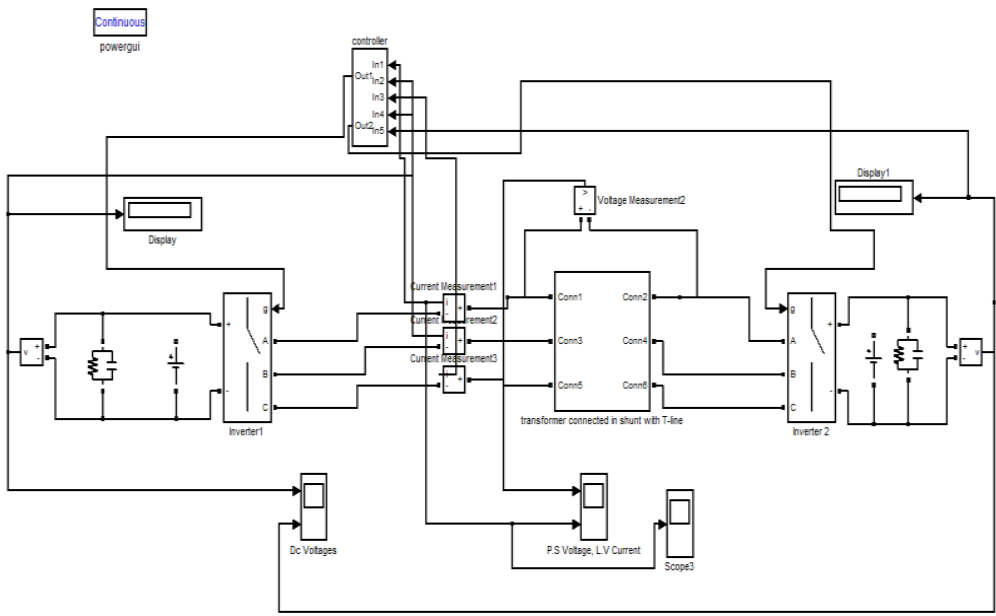

Fig. 9 Matlab / Simulink Model of Conventional Controller Based High Power STATCOM. 


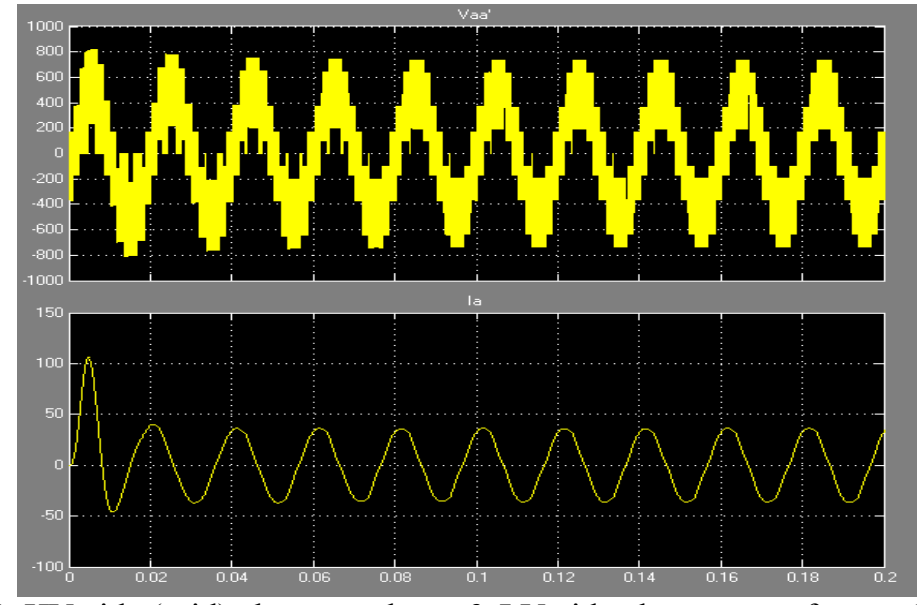

Fig.10. HV-side (grid) phase-a voltage \& LV-side phase-a transformer Current

As above fig 10 shows the Matlab/Simulink Model of Conventional Controller Asymmetric Twin Conversion Based High Power STATCOM, Fig.11 shows the HV Side Phase A voltage and LV Side Phase A TransformerCurrent, with conventional controller

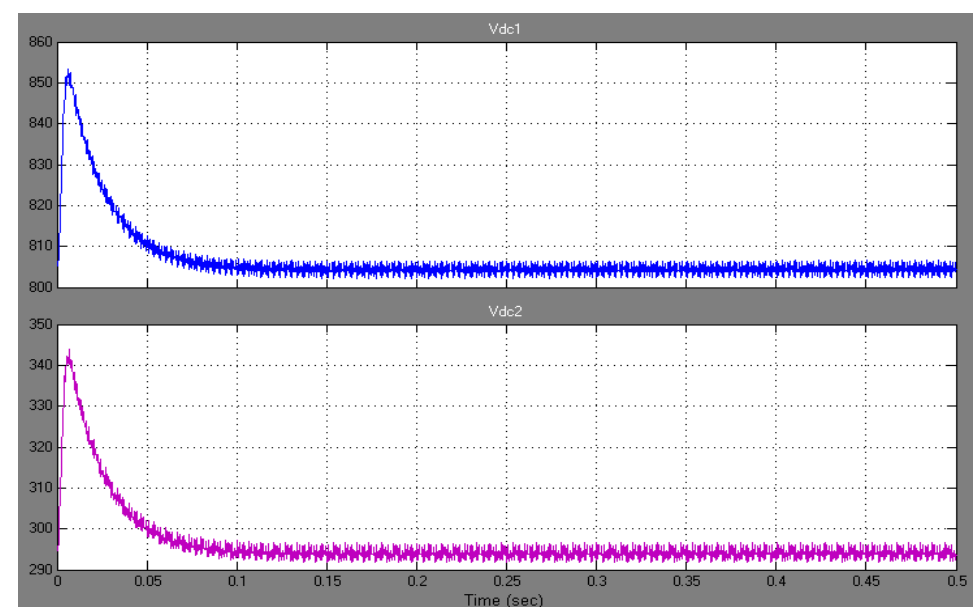

Fig.11. Converter Side Input Voltage

Fig.11shows the Converter side input voltages, nothing but primary side voltages to support the converter operations with conventional controller.

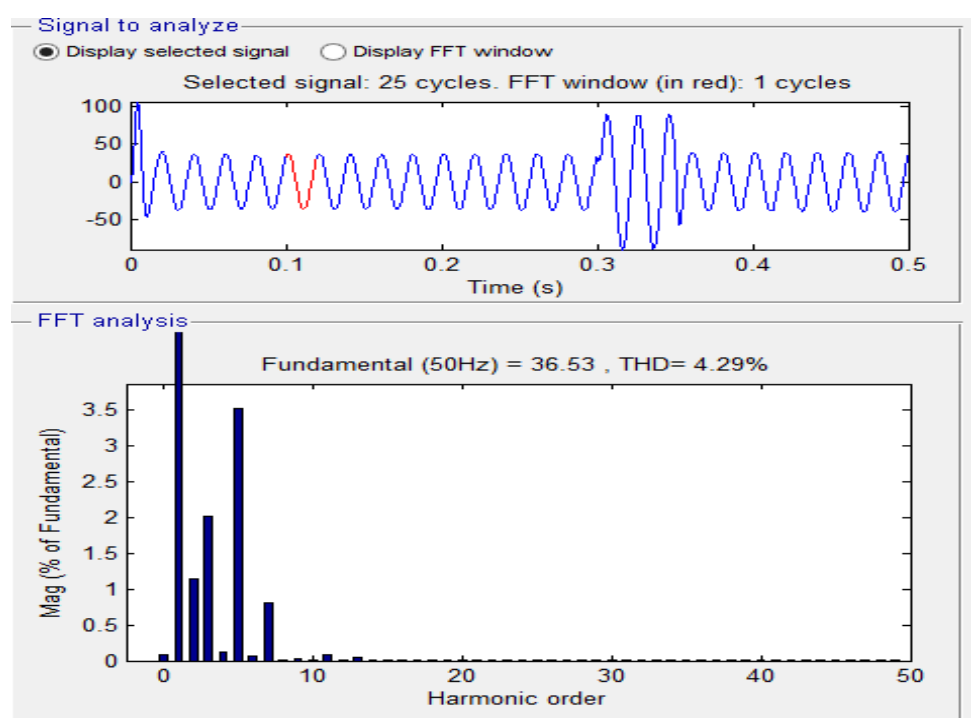

Fig.12. FFT Analysis of LV Side Phase A Current

Fig.12. shows the FFT Analysis of LV Side Phase A Current, we get $4.29 \%$, with conventional controller. 

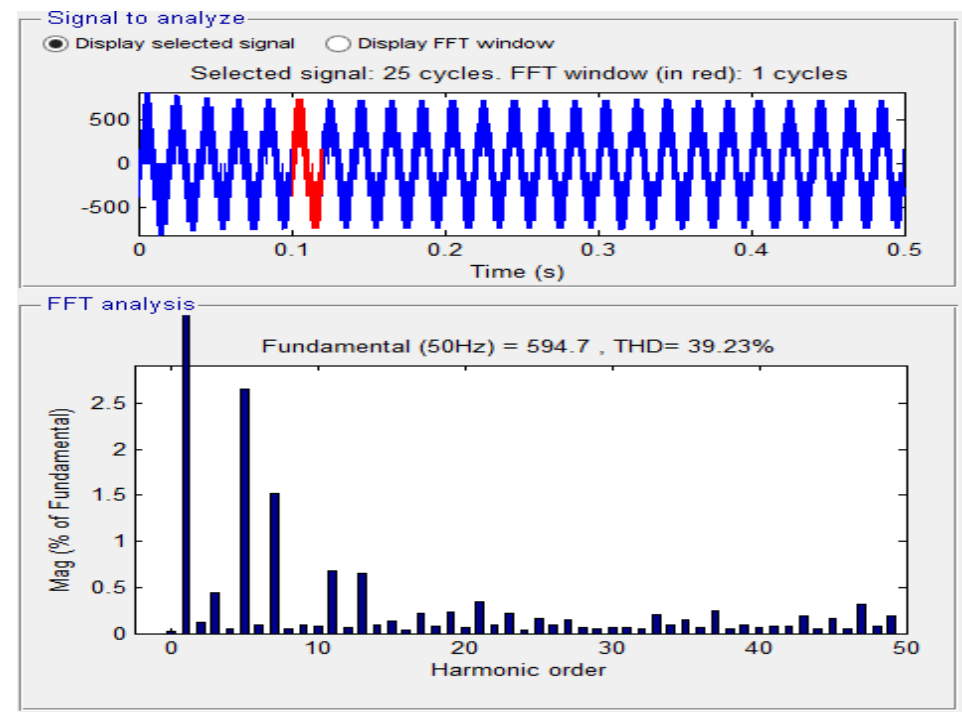

Fig.13. FFT Analysis of LV Side Voltage

Fig.13. shows the FFT Analysis of LV Side Voltage, we get 39.23\%, with conventional controller.

Case 2: Fuzzy logic Controller Based High Power STATCOM

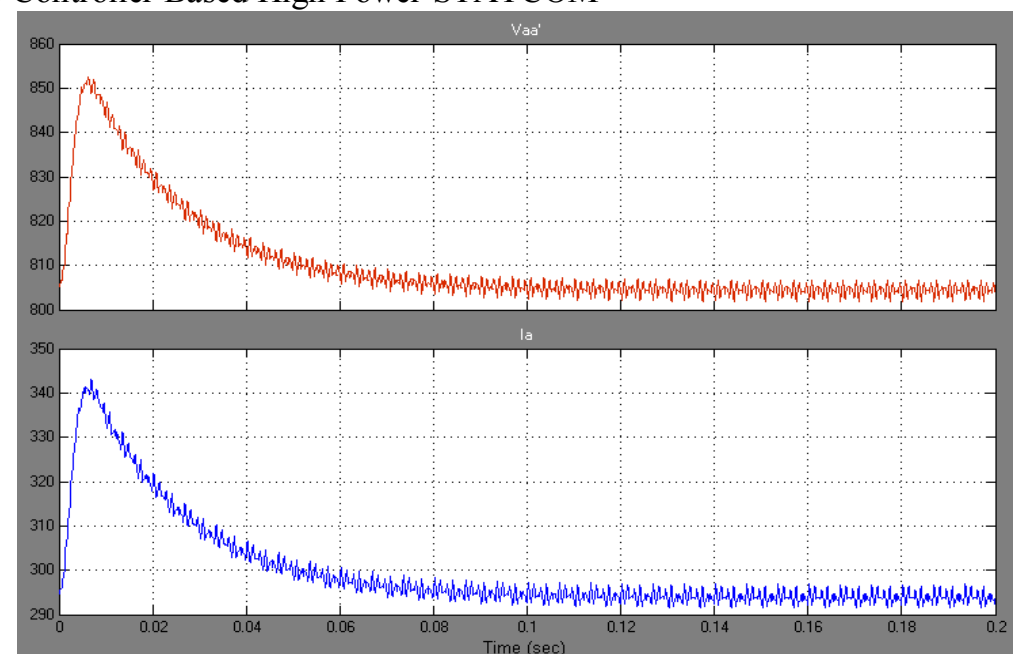

Fig.14 Converter Side Input Voltage

Fig.14 shows the Converter side input voltages, nothing but primary side voltages to support the converter operations with intelligence controller.

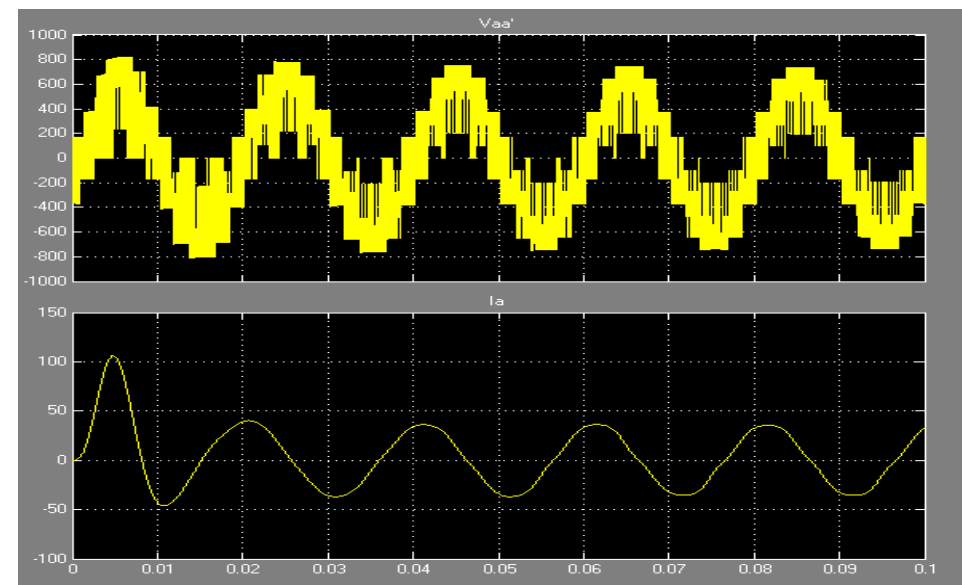

Fig.15 HV-side (grid) phase-a voltage \& LV-side phase-a transformer current

Fig. 15 shows the HV Side Phase A voltage and LV Side Phase A Transformer Current with Intelligence Controller. 


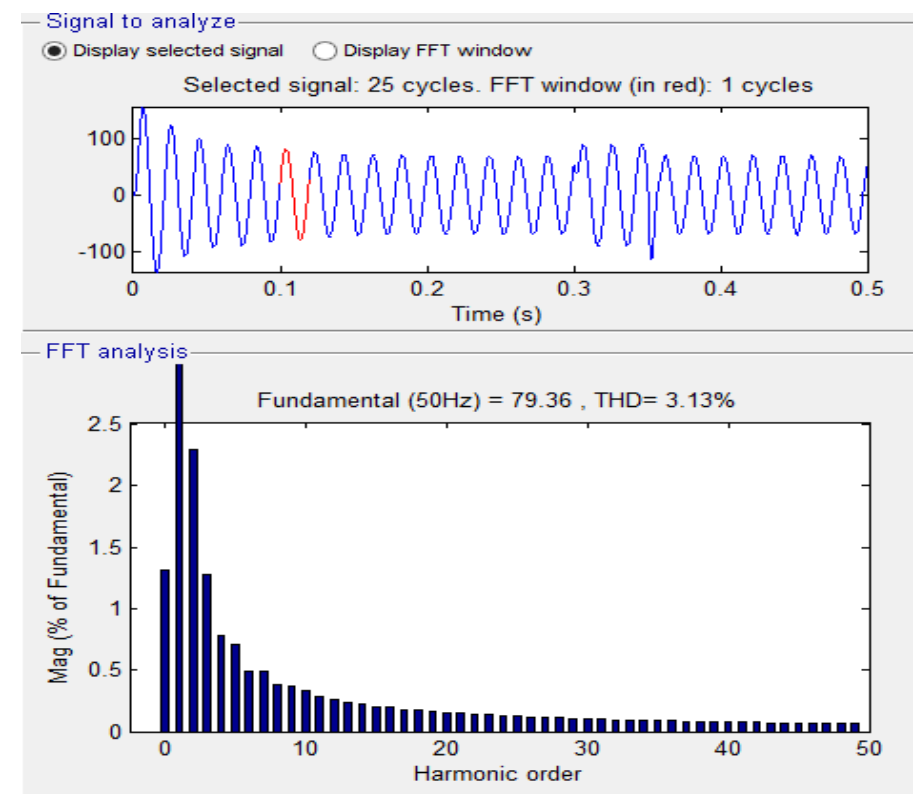

Fig.16 FFT Analysis of LV Side Phase A Current

Fig.16 shows the FFT Analysis of LV Side Phase A Current, we get 3.13\%, with Intelligence Controller.

\section{Conclusion}

A high-power STATCOM based on two 2-level VSCs is proposed with two different controlling techniques such as conventional (PI) controller \& intelligence (FUZZY) controller .Reduced component count, simpler layout of switches, and reduced capacitance requirement are the attractive features of the scheme over the diode clamped and cascaded multilevel converters. In the proposed topology, only two dc voltages have to be controlled. Furthermore, the ratio of the dc-link voltages of the two VSCs is selected such that low distortion in current is achieved. A dc-link voltage controller has been proposed to regulate the dc-link voltages of the two converters by drawing requisite amount of real power from the utility and by differentially distributing them between the two converters.

A Matlab/Simulink model of the system is developed to facilitate the design of the conventional \&Intelligence controllers, by using Intelligence controllers we get better response and fast response and better THD values, THD values well within IEEE Standards. Fuzzy control system is developed to derived, the effectiveness of the scheme is verified through detailed simulation study. By implementing Fuzzy system we have reduced the THD from $4.65 \%$ to $3.17 \%$.

\section{References}

[1]. S. Anand, B. G. Fernandes, and K. Chatterjee, "A new 4-level open-ended transformer based STATCOM for high power applications," in Proc. 36 ${ }^{\text {th }}$ Annu. IEEE IECON, Nov. 7-10, 2010, pp. 1957-1962.

[2]. C. Schauder and H. Mehta, "Vector analysis and control of advanced static VAR compensators," Proc. Inst. Elect. Eng. C-Gener., Transm. Distrib., vol. 140, no. 4, pp. 299-306, Jul. 1993.

[3]. E. M. John, A. Oskoui, and A. Petersson, "Using a STATCOM to retire urban generation," in Proc. IEEE Power Syst. Conf. Expo., Oct. 2004, vol. 2, pp. 693-698.

[4]. D. Soto and T. C. Green, "A comparison of high-power converter topologies for the implementation of FACTS controllers," IEEE Trans. Ind. Electron., vol. 49, no. 5, pp. 1072-1080, Oct. 2002.

[5]. J. Rodriguez, J.-S. Lai, and F. Z. Peng, "Multilevel inverters: A survey of topologies, controls, and applications," IEEE Trans. Ind. Electron., vol. 49, no. 4, pp. 724-738, Aug. 2002.

[6]. Y. Cheng, C. Qian, M. L. Crow, S. Pekarek, and S. Atcitty, “A comparison of diode-clamped and cascaded multilevel converters for a STATCOM with energy storage,” IEEE Trans. Ind. Electron., vol. 53, no. 5, pp. 1512-1521, Oct. 2006.

[7]. H. Abu-Rub, J. Holtz, J. Rodriguez, and G. Baoming, "Medium-voltage multilevel converters-State of the art, challenges, and requirements in industrial applications," IEEE Trans. Ind. Electron., vol. 57, no. 8, pp. 2581-2596, Aug. 2010.

[8]. S. Kouro, M. Malinowski, K. Gopakumar, J. Pou, L. G. Franquelo, B.Wu, J. Rodriguez, M. A. Pérez, and J. I. Leon, "Recent advances and industrial applications of multilevel converters," IEEE Trans. Ind. Electron., vol. 57, no. 8, pp. 2553-2580, Aug. 2010 .

[9]. F. Z. Peng, J. W. McKeever, and D. J. Adams, "A power line conditioner using cascade multilevel inverters for distribution systems," IEEE Trans. Ind. Appl., vol. 34, no. 6, pp. 1293-1298, Nov./Dec. 1998.

[10]. K. V. Patil, R. M. Mathur, J. Jiang, and S. H. Hosseini, "Distribution system compensation using a new binary multilevel voltage source inverter," IEEE Trans. Power Del., vol. 14, no. 2, pp. 459-464, Apr. 1999.

[11]. C. K. Lee, S. Y. Ron Hui, and H. S. Chung, "A 31-level cascade inverter for power applications,” IEEE Trans. Ind. Electron., vol. 49, no. 3, pp. 613-617, Jun. 2002.

[12]. H. Akagi, S. Inoue, and T. Yoshii, "Control and performance of a transformerless cascade PWM STATCOM with star configuration,” IEEE Trans. Ind. Appl., vol. 43, no. 4, pp. 1041-1049, Jul./Aug. 2007. 
[13]. M. Malinowski, K. Gopakumar, J. Rodriguez, and M. A. Perez, “A survey on cascaded multilevel inverters,” IEEE Trans. Ind. Electron., vol. 57, no. 7, pp. 2197-2206, Jul. 2010.

[14]. Y. Fukuta and G. Venkataramanan, "DC bus ripple minimization in cascaded H-bridge multilevel converters under staircase modulation," in Proc. 37th IEEE IAS Annu. Meeting, 2002, vol. 3, pp. 1988-1993.

[15]. S. Vazquez, J. I. Leon, J. M. Carrasco, L. G. Franquelo, E. Galvan, M. Reyes, J. A. Sanchez, and E. Dominguez, “Analysis of the power balance in the cells of a multilevel cascaded H-bridge converter," IEEE Trans. Ind. Electron., vol. 57, no. 7, pp. 2287-2296, Jul. 2010.

[16]. S. Lu, S.Mariethoz, and K. A. Corzine, “Asymmetrical cascade multilevel converters with noninteger or dynamically changing DC voltage ratios: Concepts andmodulation techniques,” IEEE Trans. Ind. Electron., vol. 57, no. 7, pp. 2411-2418, Jul. 2010.

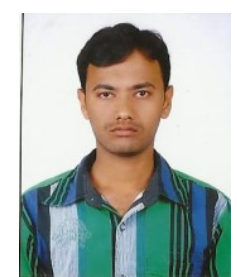

Sadakar.D received the B.Tech degree in electrical \& electronics engineering from the Jawaharlal Nehru Technological University Hyderabad, Hyderabad, India, in 2011.He is currently pursuing M.Tech ( Electrial Power Systems) in VBIT Engineering College, Aushapur(v), Ghatkesar, Hyderabad, India. His areas of interest are Power Systems, Electrical Machines and Power Electronics

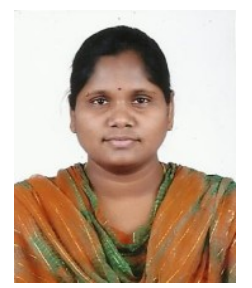

Mrs.G.Indira rani (M.Tech), Assistant Professor, Department of Electrical \& Electronics Engineering in Vignana Bharathi Institute of Technology Engineering College, Jawaharlal Nehru Technological University Hyderabad,Aushapu(v), Ghatkesar,Hyderabad,India. She has a teaching experience of 7 years. 